\title{
Status of recycling plastic bottles in Japan and a comparison of the energy costs of different recycling methods
}

\author{
Masakazu Yamashita, Shin-ichiro Matsumoto \\ Department of Environmental Systems Science, Doshisha University, 1-3 Miyakodani, Tatara, Kyo-tanabe, Kyoto, Japan \\ Email address: \\ myamashi@mail.doshisha.ac.jp (M. Yamashita)
}

To cite this article:

Masakazu Yamashita, Shin-ichiro Matsumoto. Status of Recycling Plastic Bottles in Japan and a Comparison of the Energy Costs of Different Recycling Methods. International Journal of Environmental Protection and Policy. Vol. 2, No. 4, 2014, pp. $132-137$. doi: $10.11648 /$ j.ijepp.20140204.12

\begin{abstract}
The present study explains the status of recycling plastic bottles in Japan and recycling methods, and examines whether or not they are effective in terms of reducing energy consumption. The results of the study suggest that it is unwise to use plastic bottles as containers for tea, water, soft drinks, and other beverages in the first place, and that the recycling of plastic bottles is a waste of energy. It is better to combust used plastic bottles, rather than recycle them, to produce and utilize heat.
\end{abstract}

Keywords: Recycling, Plastic Waste, PET Bottle, Heat Recovery, RDF

\section{Introduction}

In 2004, the Japanese government proposed the " $3-\mathrm{R}$ Initiative", as a measure for environmental conservation, to create a recycling society through the reduction, reuse, and recycling of waste, expecting these activities to become increasingly important. Since then, efforts to promote the 3-R activities have been implemented at a national level [1, 2]. Manufacturers and other companies are required to become involved in environmental efforts. They attempt to increase the competitiveness of their products using phrases such as "a reduced environmental burden" and "recyclable" because these are important criteria for consumers when choosing products [3].

The general public has been aware of environmental issues, probably since the media started to report the news of global warming and unusual weather around the world. Of course, global environmental issues should be addressed by the world as a whole. However, environmental efforts that are not based on visionary ideas have little effect. Actually, some of the above-mentioned environmental activities are considered to have adverse effects on the environment.

According to a dictionary, recycling is defined as "the reproduction of waste into raw materials to effectively use resources and prevent environmental pollution" [4].
Although it is desirable to stop wasting resources, we should think twice before using even larger amounts of resources to recycle waste into raw materials. Recycling is not easy. If a plastic bottle has been stepped on and crushed, it is very difficult to repair it. It takes a significant amount of energy or resources to repair the crushed plastic bottle.

Waste treatment, including recycling, in Japan is considered to have a number of problems. The present paper discusses these problems from various viewpoints, including laws, governmental policies, and materials.

\section{Status of Plastic Bottle Recycling}

It is not widely known that plastic is not a material suited for recycling. Unlike aluminum cans and glass bottles, it is very difficult to remove dirt from plastic waste while maintaining its homogeneity and recycle it into plastic bottles - "horizontal recycling" [5]. This is shown by a comparison of the status of recycling between aluminum cans and plastic bottles. According to a survey, the total rate of recycling aluminum cans in 2012 was $94.7 \%$, and the rate of recycling them into can products was $66.7 \%$ [6]. On the other hand, the rate of collecting plastic bottles in 2011 was $79.6 \%$ [7], and the rate of recycling them into plastic bottles was $11.4 \%$ [8].

The amount of energy required to produce $1 \mathrm{~kg}$ of 
aluminum metal from bauxite is $146.4 \mathrm{MJ}$, whereas that required to recycle aluminum waste into $1 \mathrm{~kg}$ of aluminum metal is $4.42 \mathrm{MJ}$. Only $3.01 \%$ of the amount of energy to produce aluminum from bauxite is required for aluminum recycling [9]. However, whether or not this amount of energy is sufficient to produce a fully formed aluminum can from aluminum waste is another question.

On the other hand, the amount of energy required to produce $1 \mathrm{~kg}$ of plastic from petroleum is $63 \mathrm{MJ}$, whereas that required to recycle plastic waste into $1 \mathrm{~kg}$ of plastic bottles is 31 MJ. This means that only $49 \%$ of the amount of energy to produce plastic from petroleum is required for plastic-bottle recycling [10]. Although the reliability of these data may be questionable, they suggest that the recycling efficiency of plastic bottles is lower than that of aluminum. The amount of plastic bottles collected in 2011 was 481,000 tons [7], and 288,000 tons of recycled bottles were produced from plastic waste by designated manufacturers [11]. The total domestic production of recycled plastic bottles in 2006 was 228,000 tons in Japan, and 392,000 tons of plastic bottles, a significantly larger amount, were exported to other countries [12].

In 2013, the price of aluminum waste per $\mathrm{kg}$ was between approximately 40 and 60 yen, depending on the market movement [13]. According to a survey conducted by the Japan Containers and Packaging Recycling Association, the price of plastic bottle waste per $\mathrm{kg}$ was approximately 50 yen in 2013 , although it significantly varied from one municipality to another [14]. Until 2005, beverage and other companies had been required to pay commission fees to outsource plastic-bottle recycling. However, since 2006, recycling companies have been paying fees to the Japan Containers and Packaging Recycling Association in order to bid for plastic bottles, and there has been a significant decrease in the amount of plastic bottles entrusted to the association [15].

\section{Improvement of the Legislation Regarding Waste Treatment in Japan}

Laws governing waste treatment in Japan include the "Waste Disposal and Public Cleansing Act", "Act for Promotion of Use of Recycled Resources", and "Containers/Packaging Recycling Act". Waste is treated in accordance with these three laws [16, 17, 18].

Plastic bottles are treated in accordance with the "Containers/Packaging Recycling Act", which is officially referred to as the "Act on the Promotion of Sorted Garbage Collection and Recycling of Containers and Packaging". The law aims to develop measures to reduce the amount of container and packaging waste, separate different types of waste, and promote the recycling of waste that complies with the separation criteria to ensure the proper treatment of waste and effective use of resources through the reduction of general waste and utilization of renewable resources. The law was established to contribute to the protection of the living environment and steady expansion of the national economy [19]. There are four types of container and packaging waste: metal, glass, paper, and plastic waste, and five-year term plans for their recycling (to be reviewed every three years) are developed by the government in accordance with its basic policies. However, aluminum and steel cans and milk cartons are already being recycled, and manufacturers have no responsibility for recycling their products by themselves.

Municipalities also develop their own five-year plans (to be reviewed every three years) to promote the separation and collection of waste according to their basic policies, and the plans are submitted to the governor of each prefecture. The governors develop five-year plans for the separation and collection of waste, which are based on the submitted plans, and submit their plans to the Minister of the Environment. Differences in the figures included in the two plans developed by municipalities and governors are coordinated. When disposing of waste, consumers separate different types of waste from each other according to the waste separation and collection plan implemented by the municipality. Local municipalities collect these various types of waste and separate them from each other more thoroughly, and these will be collected and recycled into products by manufacturers. If a manufacturer fails to recycle waste, it may receive guidance, advice, a recommendation, or order for improvement, and will be fined 200,000 to 500,000 yen if not comply.

In Japan, waste treatment is conducted in compliance with the three above-mentioned laws, and the manufacturers of containers and packages and companies that use them for their products are obliged to recycle waste packaging according to the amount of containers and packages they produce or use - the obligatory recycling amount. The obligatory recycling amount for each company is calculated using various coefficients based on the purpose-specific amounts, rather than the total amount, of containers and packages produced or used [20]. The coefficients are determined by the results of surveys on the production and use of containers and packages as well as the amount of waste packaging. Therefore, manufacturers are required to properly record and manage the types of containers and packages as well as their purposes and status of use.

For example, a beverage manufacturer that uses 1,000 tons of plastic bottles annually is obliged to recycle 84 tons of plastic waste. It is more difficult to collect, rather than recycle, this amount of plastic waste from across the country.

Manufacturers outsource plastic waste recycling to the Japan Containers and Packaging Recycling Association, and they pay the amount of money calculated by multiplying the above-mentioned obligatory recycling amount by the unit commission price. In other words, they are exempt from their obligation to recycle waste by paying money. Since the unit price for the commission of recycling one ton of plastic bottles is 101.755 yen, soft drink 
manufacturers and brewing companies are only required to pay 8.55 and 8.75 million yen, respectively, to exempt themselves from recycling plastic waste [21].

The Containers and Packaging Recycling Law defines recycling as follows:

1. To use waste that complies with the separation criteria as a raw material to produce products (products to provide fuel shall comply with the government ordinance).

2. To market waste that complies with the separation criteria as products other than fuel.

3. To help people purchase, or obtain for free, waste that complies with the criteria as a raw material to produce products [19].

According to the Ministry of the Environment, "Products to provide fuel shall comply with the government ordinance" (1) means that when the recycling of waste requires more than the treatment capacity for material and chemical recycling, it may be collected as a heat source. This type of waste collection is referred to as thermal recycling, which suggests that current recycling activities include thermal recycling to collect and utilize waste as a heat source [22].

\section{Comparison of Energy Consumption Required for Different Recycling Methods}

Currently, collected plastic bottles are treated using three methods: thermal, material, and chemical recycling methods. The energy costs and environmental burdens (expressed as $\mathrm{CO}_{2}$ emissions) of the three recycling methods were compared based on LCA data.

\subsection{Thermal Recycling}

The thermal recycling method is the generation of heat energy from waste. There are three methods to generate energy from general waste. The first method is the use of waste as refuse-derived fuel (RDF). The second one is the use of heat generated from combustion as a heat source. In the third method, heat is generated by combusting waste to produce vapor, which is used to generate electricity.

To produce RDF, combustible waste, such as kitchen garbage, used paper, and plastic, is crushed, hot-air dried, and formed into chalk-shaped sticks under pressure. The calorific value of RDF is approximately $3,000 \mathrm{kcal} / \mathrm{kg}$, and its color is gray. In most cases, plastic is also used as a material to produce RDF because it increases the calorific value.

RDF-based waste treatment involves two stages: the production of RDF from waste at RDF-production facilities and its combustion using dedicated incinerators, instead of one conducted at ordinary waste-treatment facilities. To reduce dioxin emissions, waste treatment should be implemented in a wide area so that large and effective incinerators can be used. Waste treatment over a larger area means an increase in the transportation costs. Turning waste into RDF reduces its volume by one-fifth and its weight by half, which reduces the transportation costs.
However, it is difficult to store RDF in a safe manner, and the total cost is expensive. According to a calculation by a municipality that has introduced RDF-based treatment, the expense of treating one ton of waste is approximately 27,000 yen, which is more than twice as high as that for combusting non-RDF waste [23].

Table 1 shows the amounts of energy consumed when plastic bottles and other forms of waste are turned into RDF [24]. There is a correlation between the cost of manufacturing industrial products, excluding artworks and rare antiques, and amount of energy consumed. Therefore, RDF-based waste treatment is not cost-effective.

Table 1. Amount of energy required to produce RDF from plastic (per ton) (unit: kJ) [24]

\begin{tabular}{cc}
\hline Collection & 196,635 \\
\hline RDF & $1,594,041$ \\
Total & $1,790,677$ \\
\hline
\end{tabular}

\subsection{Direct Utilization of Heat Generated during Combustion to Produce Electricity}

Most waste-treatment facilities in Japan are equipped with boilers, and heat and vapor generated by them are used for heating, hot springs, heated pools, and other services provided by neighboring health- and elderly-related facilities. These are examples of the use of heat generated during combustion as a heat source.

The present paper describes Takahama Electrical Power Plant in Gunma Prefecture as an example of power generation. The power plant has adopted the complex waste power generation system: Vapor generated by Takahama Clean Center operated by Takasaki City is further heated using the heat produced by the gas turbine power generation facility, and the heated vapor turns the steam turbines to generate electricity [25].

In the system of general power generation, vapor produced during waste incineration is used to turn the vapor turbines, although the power generation efficiency is low because the temperature of the vapor is low. However, heating the vapor using other heat sources, before it is used to turn the turbines, can increase the power generation efficiency. In the complex waste power generation system, other thermal engines are used as such heat sources.

In Takahama Electrical Power Plant, the heat of high-temperature gas discharged from gas-turbine generators is used to increase the temperature of vapor produced during waste incineration and, subsequently, the power output of the generators. This method adopted by Takahama Electrical Power Plant allows the plant to generate a larger amount of electricity compared to that produced when gas and vapor turbine generators are operated separately; the power generation efficiency is increased from approximately 10 or 15 to $35 \%$.

Combustible waste to be collected includes paper, clothes, fallen leaves, dried grass, food oil waste, and soft 
plastic (detergent and shampoo containers, plastic bags and packs, trays, and Styrofoam). The mean mix rate in 2001 was approximately $25 \%$. Incombustible waste to be collected includes glass, ceramics, metal products, electrical appliances, cans for sweets and food oil, and hard plastic (buckets, basins, polyurethane, etc.). The annual mean mix rate is approximately $15 \%$. These forms of incombustible waste are crushed and put into incinerators along with other waste. Takahama Electrical Power Plant uses vapor maintained at $225^{\circ} \mathrm{C}$, which is provided by Takahama Clean Center, for the operations of vapor-turbine, gas-turbine, and complex-type power generation.

Whereas the vapor-turbines are constantly operated, complex-type power generation is operated from 8:00 a.m. on Monday to 10:00 p.m. on Friday. The total power generation is $25,000 \mathrm{~kW}$. The gas-turbines are not operated on Saturdays and Sundays because the demand for electricity on holidays is lower. In the complex-type power generation system, natural gas is used to operate the gas turbines. The gas is collected by a private petroleum company in and around Nagaoka City in Niigata Prefecture, sold to a gas company, and transferred in a gas pipe through Nagano to Tokyo. The pipe branches off from the main route at a point in Takasaki City, and natural gas is distributed to Takasaki Clean Center through an approximately $11-\mathrm{km}$ pipe [25].

Since there are few examples of complex waste power generation, the present study has focused on a form of waste power generation to produce thermal energy during incineration. Table 2 shows energy consumption levels during the incineration of plastic waste.

Table 2. Amount of energy required to incinerate plastic waste (per ton) (unit: kJ) [26]

\begin{tabular}{ll}
\hline Collection & 196,635 \\
\hline Waste disposal facilities (incineration) & 327,034 \\
Total & 523,669 \\
\hline
\end{tabular}

\subsection{Comparison of Energy Costs Required to Produce RDF and Use Waste as a Heat Source}

Fig. 1 shows a comparison of the energy costs required to produce RDF and incinerate plastic waste in order to use it as a heat source. The energy cost required to generate a specific amount of energy by turning plastic waste into RDF is significantly lower than the cost to generate the same amount of energy by incinerating the same volume of plastic to produce heat (which is used to boil water, etc.). A large amount of energy is required to simply turn plastic waste into RDF. The only advantage of turning plastic waste into RDF is its increased transportability. There is no difference in the quantity of heat generated by combusting $\mathrm{RDF}$ and plastic waste, which suggests that RDF-based recycling is very inefficient. As described in "4.1", this method, turning plastic waste into RDF and incinerating it, is a waste of energy.

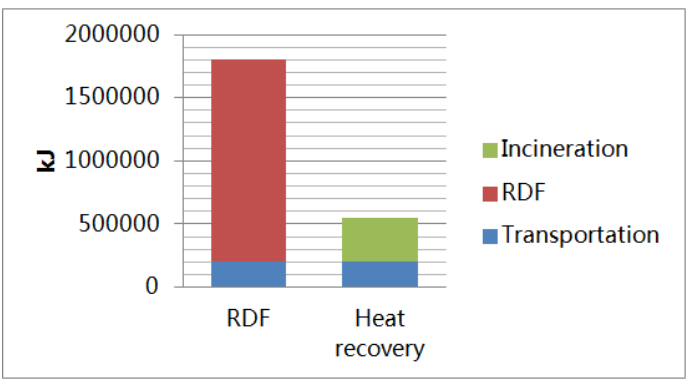

Figure 1. Comparison of levels of energy consumption required to generate $R D F$ and heat [26].

\subsection{Material and Chemical Recycling}

In material recycling, used products are processed to provide materials for the production of new products. Chemical recycling is a method that applies heat and/or pressure to plastic waste to turn it into petroleum and petrochemical raw materials [27]. In the material recycling method, collected plastic bottles are cut into tiny pieces, or flakes, to produce fibers and other products. In chemical recycling, a chemical decomposition method is used to decompose plastic bottles into terephthalic acid and ethylene glycol to resynthesize them into plastic.

Table 3 shows LCA data on the amounts of energy consumed to cut plastic bottles into flakes and turn plastic waste into recycled plastic for bottles using a chemical degradation method [28].

Table 3. Comparison of LCA results (per ton) (unit: kj) for recycled plastic flakes and plastic for bottles produced using a chemical degradation method

\begin{tabular}{lll}
\hline Classification & $\begin{array}{l}\text { Recycled } \\
\text { flakes }\end{array}$ & $\begin{array}{l}\text { Plastic for bottles produced } \\
\text { using a chemical degradation } \\
\text { method }\end{array}$ \\
\hline Manufacturing plants & $1,762,496$ & $25,886,589$ \\
$\begin{array}{l}\text { Energy required for } \\
\text { power plants (public } \\
\text { electricity) }\end{array}$ & $3,606,426$ & $2,458,954$ \\
$\begin{array}{l}\text { Energy related to raw } \\
\text { materials }\end{array}$ & 0 & 0 \\
$\begin{array}{l}\text { Energy related to fuel } \\
\begin{array}{l}\text { Energy required for } \\
\text { transportation } \\
\text { (transfer and import) }\end{array}\end{array}$ & 151,308 & $1,273,140$ \\
$\begin{array}{l}\text { Energy required for } \\
\text { mining and collection } \\
\text { of resources }\end{array}$ & 178,994 & 587,891 \\
\begin{tabular}{l} 
Total \\
\hline
\end{tabular} & $5,766,115$ & $30,593,359$ \\
\hline
\end{tabular}

Using the data presented in Tables 2 and 3, the energy costs of thermal, material, and chemical recycling were compared. As shown in Fig. 2, significantly lower amounts of energy were consumed during the simple incineration of waste, compared to RDF-based waste treatment. 


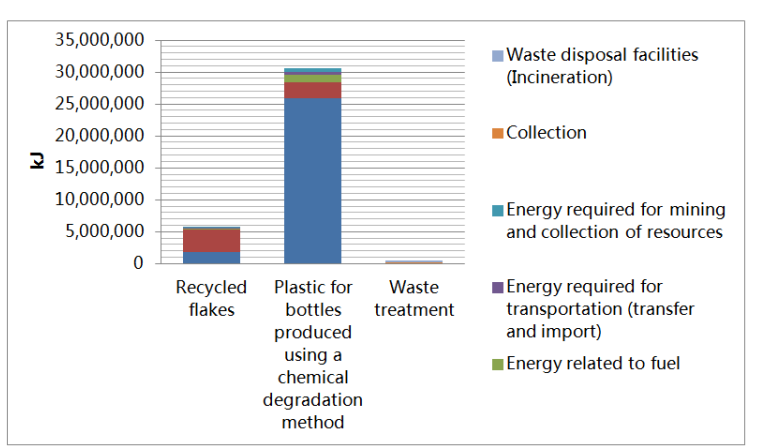

Figure 2. Comparison of energy costs required for recycling processes [28]

\section{Discussion}

The total production of plastic bottles in 2006 was 543,638 tons, and 189,464 tons were recycled. The actual recycling rate was $34.9 \%$. The collection rate in 2005 was $65.6 \%$. Almost half of collected plastic bottles were recycled, and the other half were presumably combusted, collected as a heat source, used for landfill, and exported to countries other than Japan. The amount of plastic bottles exported in 2006 was 287,015 tons, which was $52.8 \%$ of the total production of plastic bottles in 2006 .

This means that more than half of the plastic bottles produced in Japan are exported. Plastic bottles are presumably processed into flakes before being exported in accordance with the Basel Convention. A significant amount of energy required for the process of cutting plastic bottles into flakes is consumed in Japan, and the flakes are exported and used in foreign countries. Moreover, environmental burdens in Japan cannot be reduced. The quality of recycled products is lower. Plastic waste exported to China accounts for more than $90 \%$ of the total because the quality of Japanese plastic waste is higher than that of used plastic available in China, and synthetic resin is in high demand in China [29, 30].

On the other hand, since the enforcement of the Act on Promoting Green Purchasing, manufacturers in Japan, who place more emphasis on the quality of products, have been attempting to convince consumers that "products recycled from plastic bottles are environmentally friendly" to increase the competitiveness of their products. Although there has been an increase in demand for plastic in China, it may not continue for a long time. Japan will not be able to treat plastic bottles when the demand decreases because it has been relying on foreign countries for plastic waste treatment. The amount of plastic waste will sharply increase, and there will be a shortage of waste treatment sites.

Can the process of the combustion of plastic bottles to generate heat be defined as recycling? When the amount of collected plastic bottles exceeds the recycling capacity, they can be incinerated and utilized as a heat source in accordance with the law. However, incinerating plastic bottles that have been separated from all other forms of waste to generate heat is not recycling in a real sense. Although the rate of plastic bottle-to-bottle recycling in 2005 was $8.5 \%$, the figure was
$3.5 \%$ when calculated based on the amount of collected plastic bottles. The collection rate is not necessarily correlated with the number or amount of recycled products. It is believed that the energy costs of material and chemical recycling are lower than the cost of producing plastic bottles from virgin raw materials. However, the energy cost of chemical recycling, or recycling of plastic bottles, is actually higher than the cost of the production of plastic bottles from virgin raw materials.

Plastic flakes themselves are not valuable. To become valuable, they must be processed, or require an additional amount of energy in addition to the energy to produce them. If thermal recycling can be defined as recycling, it should be promoted as an environmental measure. However, thermal recycling will not serve as an environmental conservation measure unless the entire recycling process can be implemented in Japan. It is unwise to use plastic bottles as containers for water, tea, soft drinks, and other beverages from the viewpoint of energy consumption. However, considering the current situation, it is better to incinerate or dispose of large amounts of plastic bottles that have already been produced, rather than recycle them.

\section{Conclusion}

The effective use of resources depends on each individual's awareness. Although plastic bottles are very convenient, it is advisable to avoid using them as much as possible to reduce their total consumption, which will decrease the environmental burden. After purchasing drinks contained in plastic bottles, they should be used repeatedly as containers at home, rather than disposing of them. Plastic bottles should be reused as many times as possible before they are eventually incinerated to efficiently generate heat. The recycling of plastic bottles does not play an important role in solving environmental problems.

\section{References}

[1] Ministry of Economy, Trade and Industry, 3R policy, http://www.meti.go.jp/policy/recycle/ [accessed 25 January, 2014].

[2] M. Yamashita, K. Suzuki, "Human society viewed from the perspective of 3R-eco activities and environmental measures: Part I. -Effectiveness of incorporating the hybrid system into low fuel-efficient and long-distance automobile-," Resources and Environment, Vol. 4, pp. 34-44 (2014).

[3] Japan Automobile Manufacturers Association, Reduction of environmental load materials, http://www.jama.or.jp/lib/jamareport/093/ [accessed 20 February, 2014].

[4] Recycle, Britannica Concise Encyclopedia, 2010 Britannica Japan Co., Ltd.

[5] M. Yamashita, Consider the truth of environmental affairs (Japanese), Kagaku-Dojin, Kyoto, 2003. 
[6] Japan Aluminum Can Recycling Association, Recycle Data, http://www.alumi-can.or.jp/html/data_0101.html [accessed 1 March, 2014].

[7] The Council for PET Bottle Recycling, Statistics: Recovery rate, http://www.petbottle-rec.gr.jp/data/transition.html [accessed 1 March, 2014].

[8] The Council for PET Bottle Recycling, Statistics: Range of use of recycled PET, http://www.petbottle-rec.gr.jp/data/use.html [accessed on January, 2014].

[9] Japan Aluminum Can Recycling Association, About recycling, http://www.alumi-can.or.jp/html/alumi_0102.html [accessed 25 January, 2014].

[10] Ministry of Environment, Japan, Analytical results of environmental damage by use of PET bottles and so on, https://www.env.go.jp/press/file_view.php?serial=14085\&ho u_id=11451 [accessed 1 March, 2014].

[11] The Council for PET Bottle Recycling, PET bottle recycle Annual Report 2012, http://www.petbottle-rec.gr.jp/nenji/2012/pdf/pet12_2012.pd f [accessed 21 February, 2014].

[12] The Council for PET Bottle Recycling, Section 8, Recycle Statics, http://www.petbottle-rec.gr.jp/qanda/sec8.html [accessed 20 February, 2014].

[13] Material Recycle Association, The price of aluminum cans (press), http://www.recycle-society.org/index_english.html [accessed 20 February, 2014].

[14] The Japan Containers And Packaging Recycling Association, Study meeting for a bid system of PET bottles, collation, http://www.jcpra.or.jp/Portals/0/resource/00oshirase/pdf/inv estigative_16.pdf [accessed 19 April, 2014].

[15] Ministry of Economy, Trade and Industry, About the policy No. 52 , http://www.meti.go.jp/policy/newbusiness/kikidatabase/nod es/52.html [accessed 1 April, 2014].

[16] Ministry of Economy, Trade and Industry, Waste recycling governance guidelines for waste generating companies, http://www.meti.go.jp/policy/recycle/main/3r_policy/policy/ pdf/governance/governance(eng).pdf [accessed 19 April, 2014].

[17] Ministry of Environment, Measures to wastes and recycling, http://www.env.go.jp/recycle/recycling/ [accessed 19 April, 2014].
[18] Ministry of Environment, Japan, Containers and Packaging Recycling Law, http://www.env.go.jp/recycle/yoki/index.html [accessed 19 April, 2014].

[19] Ministry of Environment and Ministry of Economy, Trade and Industry, The central environmental council wastes and recycling section data, http://www.env.go.jp/council/former2013/03haiki/y030-42/ mat02.pdf [accessed 18 April, 2014].

[20] SME support, Japan, Calculation method of duty amount for re-commercialization, http://www.smrj.go.jp/keiei2/kankyo/h17/pr/pages/p13.html [accessed 19 April, 2014].

[21] The plastic recycling society ed., A hundred knowledge for plastic recycling (Japanese), Tokyo Shoseki, 1997.

[22] Ministry of Economy, Trade and Industry, Data No. 5, How to re-commercialize plastic containers and packaging, http://www.meti.go.jp/committee/materials/downloadfiles/g 50421c50j.pdf [accessed 19 April, 2014].

[23] Mainichi Shimbun, 2008, Use of solid fuel from wastes: Treatment costs in 52 facilities twice of incineration, 31 March, 2008.

[24] Ministry of Economy, Trade and Industry, A report on the LCA survey research related to the treatment and disposal of plastic waste, Plastic Waste Management Institute, http://www.meti.go.jp/policy/recycle/main/data/research/h21 fy/21fy2203-1_yourishijyou/21fy2203-1_yourishijyou-01.p df.

[25] Gunma Prefecture, Takahama power plant, http://www.pref.gunma.jp/06/q1310010.html.

[26] Report on the LCA survey research related to the treatment and disposal of plastic waste, (2008), Plastic Waste Management Institute.

[27] T. Samaki, K. Kanaya, A hundred knowledge for the garbage problem (Japanese), Tokyo Shoseki, 2004.

[28] Industrial Information Research Center, Report on an inventory analysis of plastic bottles, (2008), Analysis conducted by the Council for Plastic Bottle Recycling.

[29] Plastic Waste Manage Institute, The present state of plastic recycling in China, http://www.pwmi.or.jp/public/news200903.html [accessed 21 April, 2014].

[30] Q. Wang, "Regenerated PET fiber in China," unpublished. 